\title{
AVANCES EN LOS ESTUDIOS SOBRE LOS CÓDICES MIXTECOS
} (1973-84)

\author{
Nelly GutiérRez Solana
}

En los últimos once años han habido avances muy importantes en la interpretación de los códices mixtecos. Sobre la base firme de los estudios de Alfonso Caso, numerosos investigadores han enfocado su interés en aspectos diversos de los mismos. En esta reseña sigo un orden cronológico, con dos excepciones: la primera es que debido a la importancia del libro póstumo de Caso comienzo con él; la segunda excepción es que trato sobre la lectura del anverso del Códice Vindobonensis en un inciso por separado incluido al final. Cuando se trata de libros y artículos publicados en un mismo año, sigo un orden alfabético por apellidos de los autores.

El libro póstumo de Alfonso Caso, Reyes y reinos de la Mixteca, es el resultado de cincuenta años de su labor como investigador. En el primer volumen, publicado en 1977 , después de una introducción general en la cual explica los elementos que aparecen en los códices y el valor histórico de estos últimos, el autor pasa a considerar la historia de la Mixteca. Es decir, ya no se trata de la lectura aislada de los sucesos representados en cada uno de los manuscritos, sino de la historia resultante de la lectura en conjunto de todos ellos. Con gran detalle explica las genealogías de los reyes mixtecos y estudia aparte otros señoríos. De importancia singular es su investigación sobre los códices y lienzos de Coixtlahuaca. Los apéndices del primer volumen están relacionados principalmente con la cronología y con las tablas genealógicas.

En el segundo volumen, publicado en 1979, Caso incluye todos los datos biográficos de los personajes que aparecen en los manuscritos mixte$\cos$. El autor utilizó, para elaborar este diccionario biográfico, no sólo 51 manuscritos pictóricos, sino también datos tomados de archivos.

El libro de Caso es una obra magna que únicamente una persona con sus conocimientos y dedicación podía lograr. Es una base de suma importancia para el estudio de los códices, ya sea que se desee un panorama general de las dinastías reinantes o los datos personales de uno de los individuos representados en ellos. Al consultar esta obra, debe tomarse en cuenta que la cronología establecida por el autor ha sido revisada; por lo tanto, algunos personajes considerados por Caso como pertenecientes a generaciones diferentes fueron en realidad contemporáneos. 
En 1973 apareció el libro de M. E. Smith sobre los glifos toponímicos mixtecos. La autora enumera los glifos identificados hasta ese momento, los explica y agrega algunas interpretaciones novedosas, como los glifos de Juquila y Santa María Suchixtlán. Su libro incluye asimismo el análisis minucioso de lienzos mixtecos de la época colonial.

Emily Rabin se ha dedicado al problema cronológico presentado por los códices mixtecos. Su artículo principal sobre este problema es "Some Problems of Chronology in the Mixtec Historical Manuscripts" (en su primera parte de 1974 y en la segunda de 1976). En él explica por qué la cronología establecida por Caso es incorrecta: las fechas dadas por él son inaceptables, ya que no corresponden al lapso de vida normal de los humanos. La autora establece tna nueva cronología que todavía no puede correlacionarse con nuestro calendario por estar inconclusa.

Los artículos de John B. Glass publicados en el Handbook of Middle American Indians en 1975 son de importancia primordial para cualquier investigador interesado en códices. Del primer artículo, "A Survey of Native Middle American Pictorial Manuscripts", me ocuparé únicamente de la parte dedicada a los manuscritos del estado de Oaxaca. Según el autor, hay 93 manuscritos pictóricos provenientes de dicho estado, y dentro del mismo define tres regiones geográficas: oeste, norte y este. De cada una de estas regiones nos presenta un estudio en el que indica los límites geográficos y, en el caso de la región occidental, nos relata brevemente cómo se empezaron a leer los manuscritos mixtecos prehispánicos, cuáles son sus temas y sus cronologías. Glass abarca también al grupo de lienzos originarios del valle de Coixtlahuaca.

En cuanto a la segunda región, el autor se refiere a los manuscritos cuicatecos, mazatecos y chinantecos. Es importante observar que Glass cita la bibliografía pertinente a cada una de las regiones. En la región del este trata sobre los manuscritos zapotecas, los cuales son principalmente lienzos y mapas. De gran utilidad son las tablas que nos presenta con los manuscritos originarios de cada región; en dichas tablas los clasifica según su contenido (rituales y calendáricos, genealógicos, cartográficos, etcétera).

En el segundo artículo, "A Census of Native Middle American Pictorial Manuscripts" (escrito en colaboración con Donald Robertson), se nos da una información muy valiosa, pues de cada códice se incluyen datos importantes, como el nombre o nombres con los que se les conoce, su localización, su historia y también la bibliografía de cada uno de ellos.

E. Rabin presentó, en 1976, una ponencia sobre la llamada guerra venida del cielo (o guerra contra los hombres de piedra, como la nombró 
Caso), representada tanto en el Códice Nuttall como en el Códice Bodley. Después de un estudio detallado de los participantes en dicha lucha, llega a la conclusión de que esta guerra duró por lo menos veintiocho años. En el Códice Nuttall hay dos versiones de esta guerra pero ambas son contemporåneas, al igual que la versión dada en el Códice Bodley. Según Rabin, tres grupos fueron los que intervinieron en la lucha y el más interesante es el llamado "el de los hombres de piedra".

En 1978 salió publicado, en la revista American Antiquity, un artículo de Eva Hunt sobre la procedencia y el contenido de los códices Porfirio Diaz y Fernández Leal. La autora considera que fueron realizados en los primeros años de la época colonial, pero que probablemente son copias de manuscritos prehispánicos más antiguos. Lo más importante de este artículo es la clasificación de ambos como cuicatecos y, según nos dice Hunt, se emplearon hacia 1562 en un pleito legal sobre los derechos de sucesión de la nobleza local. Hay que advertir que la autora estudia únicamente la parte histórica del Códice Porfirio Díaz pues no abarca la sección calendárica-ritual.

H. B. Nicholson es el autor de un interesante artículo sobre la deidad 9 Viento "Ehécatl Quetzalcóatl" y el papel desempeñado por él en los códices mixtecos; dicho artículo apareció en 1978. A este dios se le representó 25 veces en los códices Vindobonensis y Nuttall y unas cuantas en los demás manuscritos mixtecos, con la excepción del Rollo Selden, en el cual tiene una actuación sobresaliente. El dios 9 Viento "Ehécatl Quetzalcóatl" ocupó una posición muy importante en la cosmología de la región mixteca y quizá se le consideraba como el ancestro directo de la realeza de dicha región. En general, el papel que jugó en la historia y en la religión mixteca es semejante al desempeñado por él en las culturas del centro de México.

En su artículo de 1978 titulado "Fundamental Changes in the Interpretations of the Mixtec Codices", Nancy Troike trata no sólo de esos cambios, sino que establece además cuáles eran, para ese momento, los problemas más apremiantes por resolver en la lectura de los códices. Estos problemas eran: corregir la cronología; determinar si los sucesos representados son históricos o míticos, y esclarecer el papel jugado por los seres sobrenaturales en la cultura mixteca prehispánica. La importancia del segundo problema estriba en que si se trata de eventos míticos sucedidos en fechas míticas, no deben tomarse en cuenta en la elaboración de las tablas cronológicas. Otros aspectos tratados por la autora son: los nombres calendáricos, los glifos toponímicos, las posturas y posiciones de las partes corporales y la indumentaria. 
Uno de los avances principales en el estudio de los manuscritos mixtecos es que se ha podido establecer dónde fueron elaborados algunos de ellos. Un caso concreto es el del Códice Becker II que, según M. E. Smith, procede de la Mixteca Baja, quizá del pueblo Santos Reyes Yucuna. Para llegar a esta conclusión la autora se basó tanto en la información del texto pictórico como en los datos de inscripciones visibles únicamente bajo la luz ultravioleta.

Maarten Jansen, en su artículo de 1979, indica nuevos caminos a seguir en la lectura de los códices. Así, por ejemplo, se interesa en encontrar concordancias entre las ilustraciones de los códices y la topografía de la Mixteca. Según nos explica, la página 36 del Códice Nuttall es un croquis del valle de Apoala pues, en el extremo superior de dicha página, hay un árbol y una cascada; esta última existe todavía en Apoala y del árbol quedan recuerdos en sus leyendas. Del otro lado de la misma página aparece una serpiente, posible alusión a una cueva donde está el manantial de un río; el nombre mixteco de dicho manantial se puede traducir como "Cueva profunda de la culebra". En opinión del autor, los dibujos detallados de la topografía de Apoala, observables en el Códice Nuttall, pueden indicar que el autor o autores del mismo procedieron de esta región. Jansen comenta asimismo que los cuentos y creencias de los habitantes de Apoala dan una información que puede ayudar a interpretar los códices Vindobonensis y Nuttall.

El Códice Bodley es objeto de un minucioso estudio por parte de N. Troike en su artículo de 1979 "Preliminary Notes on Stylistic Pattterns in the Codex Bodley". La importancia singular de este manuscrito, según nos explica, es que tiene las genealogías más completas de los reinos mixtecos de entre todos los códices conservados. La metodología empleada por Troike es la de analizar cómo el pintor organizó y distribuyó los rasgos dibujados, es decir, los patrones estilísticos. Gracias a su estudio se llega a una mayor precisión cronológica de las dinastías. Así dice: cuando a un personaje se le dibuja sobre un asiento carente de glifos toponímicos significa que, a pesar de que el individuo pudo heredar el poder, nunca llegó a gobernar en la realidad.

Otro artículo de Troike, publicado también en 1979, se titula "Current Problems in the Mixtec Codices" y se ocupa en él de temas similares a los de su artículo del año anterior. De nuevo menciona cómo el problema más urgente es el de aclarar el concepto que tenían los mixtecos acerca de lo sobrenatural, pues la autora piensa que los conocimientos sobre las creencias de los pueblos del Altiplano, ante todo de los mexicas, han influenciado demasiado a los estudios sobre la Mixteca. Resalta además la 
importancia de la lingüística, la cual puede contribuir a un conocimiento más profundo del pasado del pueblo mixteco. Concretamente la ayuda primordial consistiría en determinar las relaciones entre las lenguas y los dialectos diversos y establecer cuáles son las palabras más antiguas usadas para nombrar las cosas.

Del año de 1982 tenemos los artículos de Chadwick, Robertson y Troike y un libro de Parmenter. El propósito del artículo del primero es mostrar que las modificaciones hechas en el reverso del Códice Nuttall tuvieron como finalidad aumentar la importancia del personaje llamado 8 Venado. En concreto, se refiere a la relación de este jefe con Tilantongo y da como hipótesis que 8 Venado probablemente ni siquiera gobernó en dicho sitio. El autor considera necesario realizar mayores estudios para clarificar hasta qué grado fue cambiada la historia para favorecer a este personaje.

El libro de R. Parmenter, Four Lienzos of the Coixtlahuaca Valley, comienza con una narración fascinante de cómo sus investigaciones le permitieron establecer de dónde procedía el lienzo llamado "Antonio de León" y de cómo sus indagaciones le llevaron a descubrir nuevos lienzos en el pueblo de Tequixtepec.

Después de definir qué son los lienzos y sus funciones, nos indica que fueron realizados durante el siglo XVI y hasta el XVII. Los más completos combinan tanto la historia como las genealogías de los gobernantes locales, además de funcionar como verdaderos mapas. El autor logra determinar, después de un estudio minucioso, que el lienzo "Antonio de León" proviene del pueblo de Tlapiltepec.

El análisis de los dos nuevos lienzos del pueblo de San Miguel Tequixtepec permiten a Parmenter identificar a varios personajes y glifos que aparecen en los otros lienzos del valle de Coixtlahuaca y en el Rollo Selden. Estos personajes son diferentes a los dibujados en los códices mixtecos preshispánicos más estudiados, como son el Nuttall y el Vindobonensis. Los datos brindados por estos lienzos, aunados a los de los otros lienzos conocidos, vienen a completar la historia y la genealogía del Valle de Coixtlahuaca,

Donald Robertson escribió el artículo titulado "Some Comments on Mixtec Historical Manuscripts". Su intención, según explica, es dar a conocer los cambios sufridos en los manuscritos mixtecos. Hay unos cambios debidos al transcurso del tiempo; por ejemplo, en los códices Bodley y Selden la ausencia de los colores azul y verde se debe a su transformación en otros colores, como café oscuro o café claro; este cambio debe ser tomado en cuenta en los análisis pre-iconográficos, como en el caso de los atavios de las deidades. 
En el Codice Nuttall las modificaciones, que son frecuentes, se deben a la mano del hombre, ya sea por consideraciones estéticas, por correcciones de errores cometidos al dibujarlo o, en un tercer caso, por el propósito de cambiar el contenido histórico del manuscrito. El cambio en el contenido fue hecho principalmente para darle una importancia mayor al personaje ilamado 8 Venado, así por ejemplo, en ocasiones encontramos que dicho personaje sustituye a un glifo toponímico borrado. En el apéndice de este artículo el autor señala, página por página, modificaciones observadas por él en el contenido del Códice Nuttall.

Nancy Troike, en su artículo "The Interpretation of Postures and Gestures in Mixtec Codices", analiza las posturas y los ademanes representados en tres manuscritos mixtecos; el Bodley, el Selden y el Colombi. no Becker. En este último pudo establecer las posiciones adoptadas por las manos de los personajes en la acción de solicitar algo y en la de aceptar la petición. Un aspecto interesante de este estudio es que sólo en este códice se emplean las manos para transmitir información, mientras que en los otros manuscritos no se utilizan de esta manera.

En cuanto a las posturas del cuerpo humano, la autora pudo identificar algunas con significados específicos. Un ejemplo es cuando un personaje muestra el brazo extendido frente al cuerpo y coge una lanza o bastón, lo cual indica que emprende un viaje con propósitos religiosos, como puede ser la visita a un ser sobrenatural o el realizar una ceremonia ritual.

Otro artículo de la misma autora se titula "Studying Style in the Mixtec Codices: An Analysis of Variations in the Codex Colombino-Becker". En él $\mathrm{N}$. Troike enfoca su estudio al análisis detallado de varios elementos pictográficos del Códice Colombino-Becker. Dicho códice muestra diversos estilos, ya que es obra de varios artífices. Con la ayuda de un esquema, explica cómo los fragmentos del manuscrito deben unirse para presentar un orden correcto; entre estos fragmentos incluye al Códice Becker $l$, que es parte del Colombino, y comenta que faltan cuatro secciones del texto que se encuentran perdidas. La autora identifica tres estilos principales en el códice y otros tres secundarios y, a través de su estudio, logra determinar tanto los rasgos característicos de los estilos personales de los pintores como los elementos pertenecientes al estilo mixteco en general.

En el libro The Cloud People, publicado en 1983, se incluyeron dos artículos de M.E. Smith. El primero establece como probable sitio de origen del Códice Selden al valle de Nochixtlán, en la Mixteca Alta. Este manuscrito trata de la genealogía del lugar nombrado por Caso "Montaña que escupe" el cual, según la autora, se puede identificar con el pueblo de Magdalena Jaltepec. En el segundo articulo, Smith se refiere al carác- 
ter local del Códice Selden, pues el interés del mismo se concentra en la dinastía reinante en Jaltepec y se omite mencionar, con pocas excepciones, a personajes o sucesos ajenos a esta casa reinante. Da como ejemplo que, de los 204 personajes representados en dicho manuscrito, sólo 50 aparecen en otros códices mixtecos,y además no hay en él referencia alguna a señoríos tan importantes como Tilantongo y Teozacualco.

\section{Lectura del anverso del Códice Vindobonensis.}

Gracias a dos investigadores, J. Furst y M. Jansen, se ha logrado un adelanto notable en la lectura del anverso del Códice Vindobonensis. Esta parte del códice había sido analizada por Nowotny (1948), quien tuvo grandes aciertos, pues estableció que muchas fechas no eran históricas sino míticas. Caso, a su vez, había interpretado correctamente ciertas esce. nas, como la del culto a los hongos. Faltaba, sin embargo, un estudio minucioso y a fondo del contenido del anverso de este manuscrito.

J. Furst utiliza, en su libro de 1978, la metodología propuesta por Nowotny consistente en buscar el significado de los elementos y de los símbolos dentro del mismo códice y ver en qué contexto se emplean. Evitó caer así en el error de otros investigadores de basarse en fuentes ajenas a la Mixteca (como son las relacionadas con los mexicas y otros pueblos nahuas).

La autora divide al manuscrito en secciones narrativas y nos da su interpretación. En cada capítulo incluye tablas de elementos que permiten checar datos rápidamente. Furst utiliza las fuentes etnohistóricas provenientes de la región, pero siempre con gran cuidado. Su análisis cumple el propósito de permitirnos entender la narración del códice con sus rituales complejos. Identifica además varias deidades, proporciona un cuadro con el panteón mixteca y logra esclarecer el significado de las fechas míticas. Un aspecto dudoso de su trabajo es su opinión de que la representación de la muerte simboliza en realidad la vida. En el mundo prehispánico se consideraba a la muerte como parte de un ciclo vital, pero no por ello se deben interpretar, como sugiere, a las deidades repletas de signos mortuorios como ajenas a la muerte. Como dice Jansen: si se le quita a los esqueletos y a los huesos toda connotación de muerte, no hubieran tenido los indígenas imágenes para referirse a esa realidad. ${ }^{1}$

En su libro de 1982, Jansen completa de manera admirable el estudio de Furst. La diferencia más importante entre los enfoques de los dos au-

${ }^{1}$ Jansen, 1982, p. 129 
tores es que Jansen se acerca a los mixtecos contemporáneos para lograr profundizar, a través de su idioma y de sus mitos y creencias, en el contenido del códice. Una de sus metas es identificar sitios dibujados en el manuscrito con localidades actuales, así como configuraciones glíficas con rasgos geográficos. Acertada es su opinión de que la diferencia entre los seres divinos y los humanos no es tan tajante en el mencionado códice, pues las dinastías se consideraban de origen divino. Inclusive se creía que los gobernantes poseían cualidades sobrenaturales. En las propias palabras de Jansen, el anverso del Códice Vindobonensis es la "expresión solemne de una visión ritualística y mítica de cómo se originaron las diversas dinastías mixtecas"."

Para completar su estudio, el autor analiza detalladamente el papel de los ñuhus o seres sobrenaturales en la religión mixteca, además de la función de los bultos sagrados, considerados por él como elementos primordiales en las historias dinásticas. Es muy importante también su análisis de las ceremonias del fuego nuevo, pues logra establecer que están asociadas a las fundaciones de nuevas dinastías. Jansen incluye en su estudio el reverso del Códice Vindobonensis cuyo tema es la genealogía de la dinastía de Tilantongo.

Los avances en las interpretaciones del Códice Vindobonensis y de los otros códices mixtecos permiten a los investigadores adentrarse en otros aspectos más especializados. Como ejemplo de ello tenemos la tesis doctoral de John Pohl presentada en 1984. La meta del autor es definir el papel desempeñado por ciertos personajes representados en los manuscritos mixtecos que no pertenecían a las dinastías reinantes pero que tenían cierto carácter sagrado. A él le interesa la organización política y cómo ésta se refleja en los códices. Según sus propias palabras, "su estudio trata de esclarecer cómo estos personajes sacros funcionaban en el antiguo sistema gubernamental mixteco". ${ }^{3}$

El autor centra su interés en dos individuos y en un grupo de personajes. Este último lo integran cuatro sacerdotes identificables por su atavio. En dichos sacerdotes recaía la autoridad sagrada, y su tarea primordial era la de cuidar el bulto sagrado, objeto de gran importancia en las sucesiones dinásticas.

En cuanto a los individuos, uno de ellos es la Sra. 9 Hierba, considerada como sacerdotisa-diosa encargada de un culto funerario, centrado en una cueva, donde se enterraba a los gobernantes principales. Este culto

${ }^{2}$ Ibid, p. 355.

${ }^{3}$ Pohl, 1984, p. XI. 
daba una especie de identidad común a los reinos independientes, inclusive Pohl habla sobre una autoridad coercitiva que descansaba en dicha sacerdotisa-diosa. Debido a que el atavío de la Sra. 9 Hierba combina elementos asociados a la vida y a la muerte, el autor la considera como un personaje simbólico de la transición entre esos dos estados.

El otro individuo, llamado 4 Jaguar, poseía la autoridad suficiente para elevar a un personaje al rango de gobernante; así, lo vemos ponerle la nariguera de turquesa a 8 Venado, quien no era el heredero legítimo al reino. En opinión de Pohl, tanto 4 Jaguar como sus ayudantes no eran mixtecos, sino originarios de la región central de México.

Por último, el autor enfoca su estudio en las relaciones entre los seño. res gobernantes y los territorios bajo sus dominios. Así piensa que la región abarcada en la historia narrada por los códices mixtecos no es muy amplia y, por lo mismo, las conquistas de 8 Venado se concentraban en un área reducida. Según nos explica, más que grandes conquistas "se trata de la reorganización y consolidación del poder entre los sitios descentralizados del valle de Tilantongo". "Pohl considera además que dichos códices ayudan a conocer los patrones de asentamientos en la Mixteca, pues la distribución de los glifos toponímicos dentro de un marco geográfico simbólico reflejan el sistema de asentamientos que existió realmente.

En resumen, gracias a los estudios de los últimos once años se han logrado metas como: la interpretación del anverso del Códice Vindobonensis, la identificación de pueblos de donde provienen algunos códices, la determinación de los estilos individuales de los escribanos-pintores y un mejor conocimiento de la organización social y política, así como de la religión, la mitología y la historia de la Mixteca. Para ello se han empleado la linguíistica, las fuentes etnohistóricas regionales y el análisis cuidadoso de las representaciones pictóricas. Una nueva cronología permitirá una precisión mayor de las fechas dentro del marco histórico, y la arqueología aportará sus propios métodos para comprobar datos obtenidos de los manuscritos. Poco a poco, pero con pasos firmes, nos acercamos a una mejor comprensión de la cultura mixteca. ${ }^{\breve{j}}$

${ }^{4}$ Ibid, p. 156.

${ }^{5}$ Hasso von Winning y John Pohl hicieron el favor de leer este artículo y les agradezco sus valiosos comentatios. 


\section{BIBLIOGRAFIA}

Caso A.

1977-79 Reyes y reinos de la Mixteca, vols. I y II, Fondo de Cultura Económica, México.

CHADWICK, $R$.

1982 "An Explanation of the Textual Changes in Codex Nuttall", Aspects of the Mixteca- Puebla Style and Central Mexican Culture. in Southern Mesoamerica, pp. 27-31, Tulane University, Nueva Orleans.

FURST, I.

1978 Codex Vindobonensis Mexicanus I: A Commentary, Albany, Nueva York.

Glass, J. B.

1975 "A Survey of Native Middle American Pictorial Manuscripts", Handbook of Middle American Indians, vol. 14, pp. 3-80, University of Texas Press, Austin.

en colabozación con D. Robertson.

1975 "A Census of Native Middle American Pictorial Manuscripts", Handbook of Middle American Indians, vol, 14, pp. 81-252, University of Texas Press, Austin.

HUNT, E.

1978 "The Provenience and Contents of the Porfirio Diaz and Fernández Leal Codices: Some New Data and Analysis", American Antiquity, No. 43 , pp. 673-690.

JANSEN, M.

1979 "Apoala y su importancia para la interpretación de los Códices Vindobonensis y Nuttall", Actes du XLII Congrès International des Américanistes, vol. VII, pp. 161-172, París.

1982 Huisi Tacu: Estudio Interpretativo de un Libro Mixteco Antiguo: Codex Vindobonensis Mexicanus 1 , vols. 1 y 2, Amsterdam.

NICHOLSON, H. B.

1978 "The Deity 9 Wind 'Ehecatl-Quetzalcoatl' in the Mixteca Pictorials", Journal of Latin America Lore, 4 (1), pp. 61-92.

Nowotwy, K. A.

1948 "Erläuterungen zum Codex Vindobonensis (Vorderseite)", Archiv für Völkerkunde, 3, pp. 156-200.

PARMENTER, R.

1982 Four Lienzos of the Coixtlahuaca Valley, Dumbarton Oaks, Washington, D. C.

PoHL, I.

s.f. The Earth Lords: Politics and Symbolism of the Mixtec Codices, tesis doctoral presentada en la Universidad de California en Los Angeles. 
RABIN, E.

s. f. a Some Problems of Chronology in the Mixtec Historical Manuscripts, Parte I y II.

s. f. b The War of Heaven in Codices Zouche-Nuttall and Bodley: A Preliminary Study.

ROBERTSON, D.

1982 "Some Comments on Mixtec Historical Manuscripts", Aspects of the Mixteca-Puebla Style and Mixtec and Central Mexican Culture in Southern Mesoamerica, pp. 15-26, Tulane University, Nueva Orléans.

SMITH, M. E.

1973 Picture Writing from Ancient Southern Mexico, Mixtec Place Signs and Maps, University of Oklahoma Press, Norman.

1979 "Codex Becker II: A Manuscript from the Mixteca Baja?", Archiv für Völkerkunde, 33, pp. 29-43.

1983a "Codex Selden: A Manuscript from the Valley of Nochixtlán?", The Cloud People: Divergent Evolution of the Zapotec and Mixtec Civilization, pp. 248-255, Academic Press, Inc., Nueva York.

$1983 \mathrm{~b}$ "Regional Points of View in the Mixtec Codices", The Cloud People: Divergent Evolution of the Zapotec and Mixtec Civilizations, pp. 260-266, Academic Press, Inc., Nueva York.

TroIKE, N.

1978 "Fundamental Changes in the Interpretations of the Mixtec Codices", American Antiquity, No. 43, pp. 553-568.

$1979 \mathrm{a}$ "Current Problems in the Mixtec Codices", Actes du XLII Congrès International des Américanistes, vol. VII, pp. 143-146, París.

$1979 \mathrm{~b}$ "Preliminary Notes on Stylistic Patterns in the Codex Bodley". Actes du XLII Congrès International des Américanistes, vol. VII, pp. 183-192, París.

1982a "Studying Style in the Mixtec Codices: An Analysis of Variations in the Codex Colombino-Becker", Pre-Columbian Art History, pp. 119-152, Peek Publications, California.

$1982 \mathrm{~b}$ "The Interpretation of Postures and Gestures in the Mixtec Co. dices", The Art and Iconography of Late Post-Classic Central Mexico, pp. 175-206, Dumbarton Oaks, Washington, D. C. 